\title{
Personalized skincare: from molecular basis to clinical and commercial applications
}

This article was published in the following Dove Press journal: Clinical, Cosmetic and Investigational Dermatology

\section{Ewa Markiewicz Olusola Clement Idowu}

Research \& Development, Hexis Lab, Science Central, The Core, Bath Lane, Newcastle upon Tyne, UK

Correspondence: Olusola Clement Idowu

Hexis Lab, Science Central, The Core, Bath Lane, Newcastle upon Tyne NE45TF, UK

Tel +44 I9I 495 73II

Email sola@hexislab.com

\begin{abstract}
Individual responses of human skin to the environmental stress are determined by differences in the anatomy and physiology that are closely linked to the genetic characteristics such as pigmentation. Ethnic skin phenotypes can be distinguished based on defined genotypic traits, structural organization and compartmentalized sensitivity to distinct extrinsic aging factors. These differences are not only responsible for the variation in skin performance after exposure to damaging conditions, but can also affect the mechanisms of drug absorption, sensitization and other longer term effects. The unique characteristics of the individual skin function and, particularly, of the ethnic skin type are currently considered to shape the future of clinical and pharmacologic interventions as a basis for personalized skincare. Individual approaches to skincare render a novel and actively growing area with a range of biomedical and commercial applications within cosmetics industry. In this review, we summarize the aspects of the molecular and clinical manifestations of the environmental stress on human skin and proposed protective mechanisms that are linked to ethnic differences and pathophysiology of extrinsic skin aging. We subsequently discuss the possible applications and translation of this knowledge into personalized skincare.
\end{abstract}

Keywords: pigmentation, gene polymorphism, photodamage, environmental stress, cosmetics

\section{Melanogenesis as a protective mechanism against photodamage}

Clinical evaluations of the effects of sun exposure and photoprotection on skin damage and the classical signs of aging have been documented in a range of studies involving volunteers from different ethnicities, skin type and age groups using multiple criteria and clusters. The studies identified that ultraviolet (UV) exposure can be responsible for as much as $80 \%$ of aging sings in Caucasian and Asian skin, with predominance of the changes in pigmentation occurring independently of age, but are strongly linked to such exposure. ${ }^{1}$ Theoretical calculations of the maximal daily exposures to solar UV radiation that could prevent the development of photoaged skin until old age were estimated at 0.14 minimal erythema dose (MED) of average yearly dose 200 MED for unprotected skin, therefore limiting the exposure to $2.54 \mathrm{~min} /$ day. $^{2}$ Adaptive melanization, known as tanning, protects the skin against UV penetration, and molecular defects in this pathway are associated with epidermal hyperplasia and cancer susceptibility. ${ }^{3-7}$ $\mathrm{UV}$ is also responsible for early signs of photoaging, including pigment irregularities, solar elastosis and telangiectasias. ${ }^{1,8,9}$

Skin color is defined by the Fitzpatrick system that categorizes the skin into six types (I-VI) based on basal complexion, inflammatory response, tanning and sun 
burning susceptibility, with fair skin being more susceptible to this type of damage than darker skin. ${ }^{10}$ The color of human skin is largely determined by the amount and type of melanin pigment produced by melanocytes. ${ }^{11,12}$

Melanins are complex and multifunctional biopolymers represented by several types of pigment that are synthesized within lysosome-related organelles, melanosomes and transferred from melanocytes in the basal layer of epidermis to the surrounding keratinocytes. The amount and type of melanin are the main factors that determine skin complexion and UV sensitivity. Melanin exists in two main isoforms: dark-brown eumelanin that is more efficient at blocking UV photons and light pheomelanin that remains constant between dark- and lightly pigmented skin. Skin complexion and UV sensitivity are, therefore, determined predominantly by the levels of eumelanin in the epidermis. ${ }^{13,14}$

Melanogenesis is a complex and heterogeneous process that is not organized into simple linear succession, but into multidimensional and overlapping network of biochemical reactions. Central to this process is stimulation of the melanocortin receptor 1 that binds to $\alpha$-melanocyte stimulating hormone and transmits differentiation signals through activation of adenylyl cyclase and generation of cAMP. This leads to increased levels and activity of tyrosinase (TYR), TYR-related protein 1 (TYRP1, dihydroxyindole [DHI] oxidase) and dopachrome tautomerase (DCT) that catalyze the synthesis of melanin. The major biochemical reactions, substrates and enzymes in the biosynthesis of melanins and the transport and maturation of melanosome involve hydroxylation of phenylalanine, tyrosine hydroxylation (TYR), DOPA oxidation (TYR), dopachrome tautomerization (DCT/TYRP2), DHICA oxidation (TYRP1 or peroxidase), DHI oxidation (TYR or peroxidase), hydrolysis of glutathionyldopa (g-glutamyltranspeptidase), oxidation of cysteinyldopa (peroxidase), intramolecular cyclization of cysteinyldopaquinone (peroxidase), DOPA decarboxylation (AAD), hydroxylation of dopamine (DBH) and methylation of norepinephrine (PNMT). ${ }^{15,16}$ Melanogenesis has been associated with broad spectrum of $\sim 600$ proteins that are present at each stage during melanosome biogenesis. ${ }^{17}$

Epidermal melanocytes are located in the basal layer above the basement membrane in the epidermal melanin unit comprising 50 neighboring keratinocytes. ${ }^{18}$ Initial stages of UV-mediated skin darkening involve actual redistribution of the existing melanin pigment, which is followed by subsequent de novo melanin synthesis that begins several hours or days later. ${ }^{19}$ Several studies demonstrated decreased DNA damage in the lower epidermis, redistribution of melanin from the lower to the middle epidermis and increase in
UV-induced apoptosis in darkly pigmented skin, suggesting the mechanism of both more efficient UV filtration and removal of the permanently damaged cells..$^{20,21}$

In addition to direct protection from UV, melanogenesis may play other important physiologic roles in epidermal homeostasis. A study aiming at understanding the responses of differently pigmented skin types to UV measured the distribution of DNA damage and melanin content alongside the expression of melanocyte-specific genes after single MED exposure. Interestingly, while such responses were not accompanied by significant changes in both the density of melanocytes at the dermal-epidermal junctions and the melanin content, expression of melanocyte-specific proteins TYR, TYRP1, DCT as well as MART1 and MITF did change significantly within 1 week after UV exposure. ${ }^{20}$ This suggests that the genes involved in the melanin synthesis pathway also demonstrate the expression patterns regulated in response to the environment, which could be independent from the positive selection for skin pigmentation.

\section{Ethnic variations in the pigmentary traits and phenotypic differences in extrinsic aging Genetic polymorphism in constitutive pigmentation across worldwide populations}

Human skin pigmentation is an atypical trait primarily determined by the quantity and distribution of melanin, which shows a remarkable, latitude-correlated phenotypic variation among continental populations. ${ }^{22}$ Recent genotype/phenotype association studies have uncovered a spatial distribution in the single-nucleotide polymorphisms (SNPs) located within constitutive pigmentation candidate genes alongside gradual increase in skin darkness across worldwide populations from Northern Europe to Southern Europe to Northern Africa, the Middle East and Western Asia geographic regions. Human SNPs represent $>9$ million DNA sequence variations scattering the entire genome (the National Center for Biotechnology Information dbSNP database) that can alter the response of the individual to environmental exposure. SNPs occur in both gene coding and noncoding regions and can lead to changes in the biologic properties of the encoded protein or affect gene expression levels. ${ }^{23}$ Using a combination of systematic approaches, including genome-wide association studies, gene expression databases and genotype-phenotype correlations based on skin melanin index, significant variations in SNP pigmentation genes have been found between European, 
East Asian, South West Asian and African large populations in case-control studies. ${ }^{24-26}$ Many of these genes have been uncovered based on naturally occurring mutations that affect the constitutive pigmentation through the melanin or melanogenic precursor levels. In addition, a number of noncoding SNPs involved in transcriptional regulation of pigmentation genes have also been identified. ${ }^{27-30}$ General interpretation of the inter-and intra-ethnic populations' SNPs could be proposed to affect the genes involved in dark melanocyte pigmentation, vitamin $\mathrm{D}$ status and skin tanning response in Caucasian skin, darker and lighter skin reflectance in Oriental and Asian skin, with constitutive levels or activity of certain markers typically higher in African skin. There is also a profound cross-talk between melanogenic and oxidative stress response signaling pathways (Table 1).

Genetic polymorphisms underlying phenotypic variation of pigmentation require further understanding of the effects on target proteins and correlation with the cellular functions. This is achieved by combination of biochemical and cellular approaches including mRNA transcription and stability, protein assays, ligand interactions, enzymatic activity and histochemistry. For example, recording of the association between allelic distribution and melanosome density at different stages of biogenesis could provide further insight into the cellular basis of diversity in skin pigmentation. ${ }^{31}$

\section{Structural differences and aging properties of ethnic skin types}

It has been suggested previously that environmental changes could have an impact on selected pigmentation genes. ${ }^{32}$ One of the major factors that could affect extrinsic aging and, in particular, photoaging is genetically determined skin type with established content and composition of melanin. ${ }^{33}$ Susceptibility toward extrinsic skin aging is also recognized to be strongly influenced by other endogenous factors such as antioxidant or DNA repair capacity, which may be determined by individual genetic traits and ethnic differences in skin properties. ${ }^{34}$

It is well established that the number of melanocytes in different skin types remains relatively constant and is defined by the epidermal melanin unit. ${ }^{18,34}$ Darker skin, however, is characterized by the presence of more dispersed, larger and labile melanocytes that contain more melanin consistent with higher tyrosinase activity and slower rate of melanosome degradation in the epidermis. In contrast, lightly pigmented skin presents with more aggregated and smaller melanosomes that contain less melanin due to the rate of synthesis and enhanced degradation. ${ }^{34,35}$ The greater ethnic capacity toward melanogenesis in darker skin that is not exposed to UV could suggest additional contribution to the epidermal structure and barrier permeability and function. In addition to better photoprotection against UV through pigmentation, epidermis in the African skin has, indeed, a thicker stratum corneum, with more cornified cell layers and lipid content compared to Caucasian skin. ${ }^{36-38}$ Consequently, the African skin is suggested to have stronger antimicrobial defenses linked to more acidified outer epidermis and rapid barrier recovery after damage. ${ }^{39,40}$ Consistent with the degree of pigmentation, African skin and Asian skin have thicker and more compact dermis compared to Caucasian skin. ${ }^{41}$ African skin contains larger, more frequent and active fibroblasts in parallel orientation as well as more macrophages. ${ }^{42}$ Such phenotype is associated with more pronounced structural integrity of collagen in dermis that is preserved during aging and photoaging. ${ }^{38}$ In contrast, extrinsically aged Caucasian skin is characterized by profound disorganization of the elastic fibers and decreased expression of collagen in dermis. The atrophic manifestations in dermis are moreover linked to the skin type within the Caucasian population, with multiple telangiectasia (dilated superficial blood vessels) in lightly pigmented skin and solar elastosis (accumulation of abnormal elastin) in darker skin. ${ }^{43,44}$

In addition to the loss of elasticity and volume, the most common signs of skin aging and, particularly, photoaging are decreased number of melanocytes, dyspigmentation and changes in pigment distribution observed in all skin types. The aging process and sun-induced damage are, however, distinguished by unique structural and functional differences observed between light (types I-II) and dark skin (types III-VI). Darker skin, despite being more resistant to wrinkles, is generally more pronounced to dyspigmentation including both hypopigmentation and hyperpigmentation. ${ }^{34}$ The changes in pigment distribution are the principal manifestation of photodamage in Oriental and Asian skin, with the former also characterized by hyperpigmentation and increased melanin index with age. ${ }^{45-47}$ Increased occurrence of pigment spots can be partially associated with higher frequency distribution of SLC45A2 gene variant. ${ }^{48}$ Furthermore, population studies of age-related changes reveal that although uneven pigment distribution is more prevalent in Oriental and Asian skin, solar damage and wrinkle onset are significantly delayed compared to Caucasian skin, which could presumably be correlated with the antioxidant levels in fasting blood. ${ }^{49-51}$

Finally, different skin types have also distinct physiologic responses that are influenced by the environment, 
Table I Genotypic variations underlying diverse functions associated with the melanogenic pathways in major ethnic groups

\begin{tabular}{l} 
Gene \\
\hline AHCY \\
Adenosylhomocysteinase \\
ASIP \\
Agouti signaling protein: MCIR \\
antagonist; modulates eumelanin \\
versus pheomelanin synthesis ${ }^{82,83}$ \\
BNC2
\end{tabular}

Bonapartec - Zn finger protein (basonuclin-2)

DCT

Caucasian
Higher expression levels
in the darkly pigmented
melanocytes $^{81}$
Allelic diversity. Associated
with darker skin color $^{32,81}$

Oriental

Asian

African

Dopachrome tautomerase: conversion of dopachrome to DHICA in the eumelanin pathway. Stabilizes the TYR enzyme

Increased expression after UV exposure $^{32}$

DRD2

Dopamine receptor D2

\section{EDEM2}

ER Degradation Enhancing

Alpha-Mannosidase-like Protein 2 EGFR

Epidermal growth factor receptor: essential role in the control of cell growth ${ }^{87}$ EIF2S2

Eukaryotic translation initiation factor 2 subunit 2

\section{EIF6}

Eukaryotic translation initiation factor 6

EXOC2

Exocyst complex component 2

GGT7

Gamma-glutamyltransferase 7

\section{GSS}

Glutathione synthetase:, GSH biosynthesis; role in the switch between eumelanogenesis and pheomelanogenesis by interacting with tyrosinase and dopaquinone 32

HERC2

E3 ubiquitin-protein ligase IRF4 Interferon regulatory factor-4

\section{Allelic diversity ${ }^{81,84}$}

Allelic diversity ${ }^{32}$

Intronic polymorphism at high frequency ${ }^{85,86}$

Allelic diversity, positive selection $^{85}$

Higher expression levels in the dark-and moderatepigmented melanocytes ${ }^{81}$

Higher expression levels in the dark- and moderatepigmented melanocytes ${ }^{81}$ Higher expression levels in the dark- and moderatepigmented melanocytes ${ }^{81}$ Correlates with the levels of serum $25(\mathrm{OH}) \mathrm{D}$, impact on vitamin $\mathrm{D}$ status and deficiency common in the Caucasian population ${ }^{88}$ Higher expression levels in the dark- and moderatepigmented melanocytes ${ }^{81}$ Allelic diversity ${ }^{81}$

Allelic diversity ${ }^{81}$

SNP strongly associated with skin tanning response in Europeans $^{89}$
Allelic diversity ${ }^{85}$
Constitutive levels of protein expression are typically higher in African individuals ${ }^{32}$
Allelic diversity ${ }^{85}$

\section{Allelic diversity}


Table I (Continued)

\begin{tabular}{|c|c|c|c|c|}
\hline Gene & Caucasian & Oriental & Asian & African \\
\hline $\begin{array}{l}\text { ITCH } \\
\text { E3 ubiquitin-protein ligase Itchy } \\
\text { homologue }\end{array}$ & $\begin{array}{l}\text { Higher expression levels in } \\
\text { the dark- and moderate- } \\
\text { pigmented melanocytes }{ }^{81}\end{array}$ & & & \\
\hline $\begin{array}{l}\text { KITLG } \\
\text { c-KIT receptor } \\
\text { Development and migration of } \\
\text { melanocyte lineages }\end{array}$ & $\begin{array}{l}\text { Allelic diversity, positive } \\
\text { selection }^{85}\end{array}$ & Allelic diversity ${ }^{85}$ & & $\begin{array}{l}\text { Significant association } \\
\text { with higher melanin } \\
\text { index in African- } \\
\text { American population }^{32}\end{array}$ \\
\hline $\begin{array}{l}\text { MAPILC3A } \\
\text { Microtubule-associated protein I } \\
\text { light chain } 3 \text { alpha }\end{array}$ & $\begin{array}{l}\text { Higher expression levels in } \\
\text { the dark- and moderate- } \\
\text { pigmented melanocytes }\end{array}$ & & & \\
\hline $\begin{array}{l}\text { MCIR } \\
\text { Melanocortin receptor I } \\
\text { Interacts with ligands encoded by } \\
\text { POMC ( } \alpha-M S H \text { and ACTH) and } \\
\text { ASIP (Agouti, antagonist) })^{91,92}\end{array}$ & $\begin{array}{l}\text { Allelic diversity high. Same } \\
\text { effects on pigmentation appear } \\
\text { at increased frequency with } \\
\text { increasing latitude. Associated } \\
\text { with fair skin and freckling }{ }^{32,93,94}\end{array}$ & & Allelic diversity low ${ }^{95}$ & Allelic diversity low ${ }^{94}$ \\
\hline $\begin{array}{l}\text { MITF } \\
\text { Microphthalmia transcription } \\
\text { factor }\end{array}$ & $\begin{array}{l}\text { Correlates with the levels } \\
\text { of serum } 25(\mathrm{OH}) \mathrm{D} \text {, impact } \\
\text { on vitamin } \mathrm{D} \text { status and } \\
\text { deficiency common in the } \\
\text { Caucasian population } \\
88\end{array}$ & & & \\
\hline $\begin{array}{l}\text { OCA2 } \\
\text { Membrane transporter } \\
\text { Critical for maturation, } \\
\text { processing and trafficking of } \\
\text { tyrosinase to melanosomes }{ }^{31}\end{array}$ & $\begin{array}{l}\text { Allelic diversity, positive } \\
\text { selection }^{81}\end{array}$ & $\begin{array}{l}\text { Hypofunctional alleles } \\
\text { with } 70 \% \text { of the } \\
\text { function of the wild- } \\
\text { type protein. Lighter } \\
\text { skin pigmentation } \\
96,97,98\end{array}$ & & \\
\hline $\begin{array}{l}P R O C R \\
\text { Protein C receptor }\end{array}$ & $\begin{array}{l}\text { Higher expression levels in } \\
\text { the dark- and moderate- } \\
\text { pigmented melanocytes }\end{array}$ & & & \\
\hline $\begin{array}{l}\text { RALY } \\
\text { RNA-binding protein }\end{array}$ & $\begin{array}{l}\text { Higher expression levels in } \\
\text { the dark- and moderate- } \\
\text { pigmented melanocytes }\end{array}$ & & & \\
\hline $\begin{array}{l}\text { SLC24A4 } \\
\text { Solute carrier family } 24 \text { member } \\
\text { 4: membrane transporter; impact } \\
\text { on melanosome biogenesis and } \\
\text { tyrosinase activity }{ }^{31,32}\end{array}$ & Allelic diversity ${ }^{81}$ & & & \\
\hline $\begin{array}{l}\text { SLC24A5 } \\
\text { Solute carrier family } 24 \text { member } \\
\text { 5: membrane transporter; impact } \\
\text { on melanosome biogenesis and } \\
\text { tyrosinase activity }{ }^{31,32}\end{array}$ & $\begin{array}{l}\text { The key skin pigmentation } \\
\text { SNP; strong evidence for } \\
\text { selection in Europeans }{ }^{32}\end{array}$ & & $\begin{array}{l}\text { Accounts for lighter } \\
\text { skin }{ }^{99}\end{array}$ & \\
\hline $\begin{array}{l}\text { SLC45A2 (MATP) } \\
\text { Solute carrier family } 45 \text { member } \\
\text { 2: membrane transporter; impact } \\
\text { on melanosome biogenesis and } \\
\text { tyrosinase activity }{ }^{31,32}\end{array}$ & $\begin{array}{l}\text { Allele strongly associated with } \\
\text { olive skin }{ }^{85}\end{array}$ & & $\begin{array}{l}\text { Accounts for differences } \\
\text { between darkest and } \\
\text { lightest skin reflectance. } \\
\text { Mutations that impair } \\
\text { gene function (OCA4) } \\
\text { are highest in Asian } \\
\text { populations }{ }^{32,99}\end{array}$ & Allelic diversity ${ }^{32}$ \\
\hline $\begin{array}{l}\text { TYR } \\
\text { Tyrosinase } \\
\text { Catalyzes the initial step } \\
\text { critical for the rate of melanin }_{\text {production }^{32}}\end{array}$ & $\begin{array}{l}\text { Allelic diversity. Mutations } \\
\text { lead to } O C A^{81} \\
\text { Correlates with the levels } \\
\text { of serum } 25(\mathrm{OH}) \mathrm{D} \text {, impact } \\
\text { on vitamin } \mathrm{D} \text { status and } \\
\text { deficiency common in the } \\
\text { Caucasian population }^{88}\end{array}$ & & $\begin{array}{l}\text { Accounts for differences } \\
\text { between darkest and } \\
\text { lightest skin reflectance; } \\
\text { highly associated with } \\
\text { lighter skin color }{ }^{24}\end{array}$ & Largely absent ${ }^{32}$ \\
\hline
\end{tabular}


Table I (Continued)

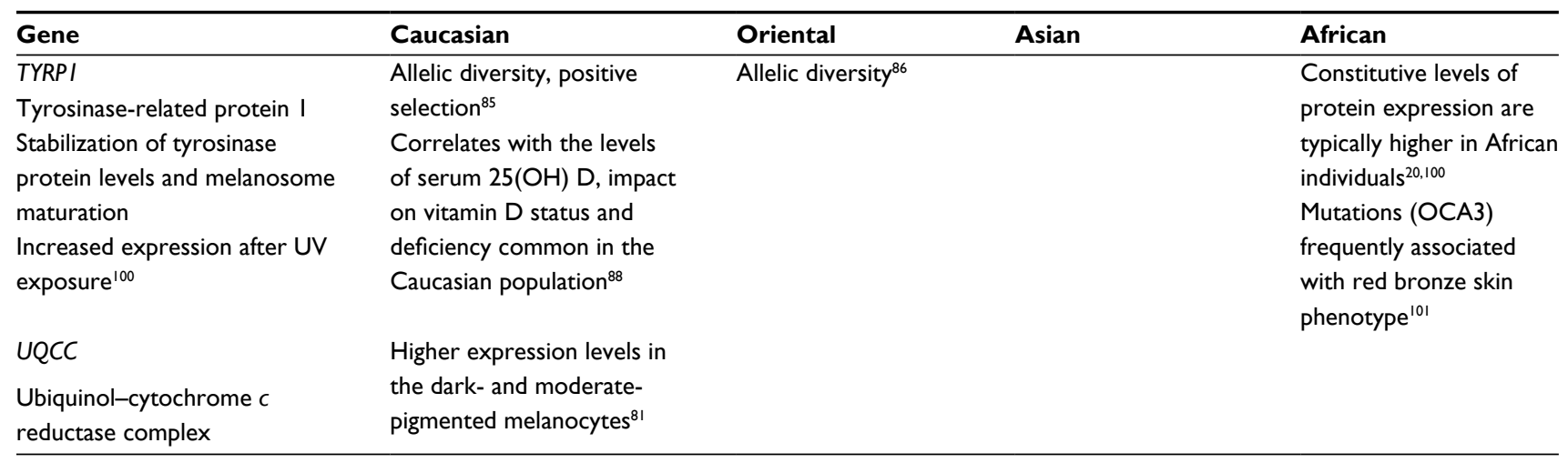

Abbreviations: 25(OH) D, 25-hydroxyvitamin D; a-MSH, $\alpha$-melanocyte stimulating hormone; ACTH, adrenocorticotropic hormone; ASIP, agouti signaling protein; DCT, dopachrome tautomerase; GSH, glutathione; MCIR, melanocortin receptor I; OCA, oculocutaneous albinism; POMC, pro-opiomelanocortin; SNP, single-nucleotide polymorphism; TYR, tyrosinase; UV, ultraviolet.

such as skin hydration. Transepidermal water loss (TEWL) is indicative of skin surface moisture and defined as the body loss of water that passes via diffusion and evaporation to the atmosphere through the epidermis, and this parameter is increased in African skin compared to Caucasian skin. ${ }^{52}$ Across all populations, TEWL and skin surface moisture decrease with age, and this is more pronounced in Caucasian skin, coinciding with thinner stratum corneum. ${ }^{43,45,53}$ Changes in the epidermis are also evident in the rate of desquamation or corneocyte variability, which increases with age and accounts for xerosis, which is frequently more pronounced in African skin. ${ }^{52,54}$ The conditions can currently be treated with a range of externally applied moisturizing products to restore the integrity of the stratum corneum through replacement of the natural natural moisturizing factor components. The active ingredients, categorized as emollients, occlusives and humectants, provide a barrier that softens the skin, bind water in the stratum corneum and prevent TEWS. ${ }^{55-57}$

\section{Personalized skincare}

Transcriptomic data generated from young and old sunprotected and sun-exposed skin provide much information on the gene clusters and hierarchical pathways implicated in intrinsic aging and photoaging. The biomarkers identified in both types of aging are relevant to skin barrier maintenance through lipid biosynthesis and epidermal differentiation as well as oxidative stress and antioxidant defenses. Differences between intrinsically aged and photoaged skin can be detected at the level of extracellular matrix, with reduced expression of collagen genes in intrinsic aging and increased expression of elastic tissue genes in photoaging. ${ }^{58}$

Much information on skin biology and aging processes obtained through molecular and cell biology-based technologies requires development and applications of advanced statistical and modeling tools. Integrative biology applied to the gene expression data aims at understanding the biological relationships and dynamic processes through the reconstruction of gene regulatory networks. Such networks, representing groups of genes with various functions and the interactions between the groups, have been built using linear and Boolean network models, Bayesian networks and other purpose-built new algorithms. The knowledge gained on the possible gene interactions can be extended further, for instance, to include other parameters such as the transcription-translation feedback or the effect of local environments on the proteins. The outcomes of mathematical modeling are furthermore applicable toward the already established knowledge on gene interactions and the likely overlap between certain genes identified in different independent studies. The need for development of additional computational approaches is also suggested to take into account more subtle changes in gene expression that are specific for single individuals within similar groups. ${ }^{59-61}$

Genetic variations that contribute to the unique characteristics of each individual are currently considered to shape the future of clinical and pharmacologic interventions. This is consistent with the idea of treating the person rather than the particular problem, which gains increasing recognition as a more effective approach. ${ }^{62}$ Based on this, the concept of "personalized medicine" recognizing underlying forms of genetic variations emerges as an exceptional strategy with unique applications in pharmacogenomics and pharmacoproteomics. This concept can be extended further onto the field of experimental and clinical dermatology and personalized skincare ${ }^{62,63}$ Recent progress in molecular assays and diagnostic tests facilitates addressing the physiology of 
skin processes and the pathogenic mechanisms of specific problems including inflammatory and autoimmune skin conditions. ${ }^{64}$ Understanding the biology of individual skin structure, sensitivity and hormonal balance and identifying the network of representative genes in the context of specific genetic makeup will drive the design of novel pharmaceuticals and mimetics to modulate appropriate biologic processes.

Skin ethnicity strongly manifests in distinct structural and physiologic traits that can be defined for each major population. In general, Caucasian skin is characterized by smaller melanosomes, less melanin, thinner stratum corneum and dermis and decreased TEWL. These factors contribute further to increased photodamage, loss of collagen and decreased elasticity of dermis as the major outcomes of extrinsic aging process. Darkly pigmented skin of African origin is characterized by bigger melanosomes and more melanin as well as thicker stratum corneum and dermis that is proportional to the degree of pigmentation. ${ }^{41}$ Both African skin and Asian skin are more resistant to photodamage and demonstrate preserved elasticity that translates into delayed appearance of wrinkles during aging. However, darkly pigmented skin is more prone to age-related changes in pigmentation, which are particularly evident in Oriental and Asian skin. In addition, ethnic differences in skin type may also manifest in regard to relative skin hydration, with dry skin and xerosis frequently more pronounced in African skin in both low relative air humidity and during aging (Figure 1). Differences between skin phenotypes are also evident within the major ethnic groups. For example, degree of pigmentation and dermal elasticity are the individual characteristics determined by both genetic and environmental factors.

Ethnic and individual diversity in skin structure and physiology may be responsible for different reactivity of the tissue to chemical factors, for instance, it could affect the rate and effectiveness of drug penetration, absorption and sensitization, the parameters important for carefully considered skincare. Whereas Caucasian skin demonstrates stronger resistance to water barrier damage, African skin is more resistant to transcutaneous penetration. ${ }^{52,65}$ Caucasian skin and Oriental skin have similar basal TEWL, but Oriental skin is more sensitive to mechanical and chemical stress, presumably because of the weaker barrier and thinner stratum corneum in the epidermis. Compared with other ethnic skin types, Oriental skin also demonstrates higher eccrine gland density and smaller pore size, which reflect the activity of the sebaceous glands. ${ }^{43,66}$ In contrast, African skin frequently shows the most severe damage around facial pores. ${ }^{67}$ The differences between ethnic skin types in response to the environmental factors can also manifest in the dermis, with Caucasian skin being more prone to inflammatory lesions and African skin presenting more often with hypertrophic scarring and keloids. ${ }^{34,43}$

The phenotypic variations and challenges in defining specific genome-drug interactions can also be applicable to the field of dermatology. One important aspect of pharmacogenomics is the assessment of individual response efficiency, appropriate dose and adverse effects of the proposed formulations, which have a direct influence on their development, cost-effectiveness and safety regulation. ${ }^{68}$ The approach to development of skin products usually occurs in stages, commencing with in-depth characterization of raw materials, their nature of exposure to the body and a maximum concentration for use, through in vitro safety tests and clinical trials to product marketing and vigilance procedures. ${ }^{69,70}$

Current strategies for personal protection against air pollution include topical products that improve skin barrier function for reduced air pollutant penetration and antioxidants to reduce reactive oxygen species, such as vitamins $\mathrm{C}$ and $\mathrm{E}$, in formulations. In parallel, substantial progress has been made in topical sunscreen formulations that combine skin moisturizers with broad-spectrum UV filters and sunscreens that filter both UVA and UVB in a ratio that mimics the natural exposure for optimal photoprotection. Effectiveness of the sunscreen is based on the measurements of the sun protection factor in the precisely defined parameters such as application layer $\left(\mathrm{mg} / \mathrm{cm}^{2}\right)$, UV irradiation dose and clinically established changes in the skin in the defined time after exposure. ${ }^{71}$ For the purpose of personalized skincare, both the skin type and the environment should be taken into account as the skin is exposed to varied levels of air pollutants on a daily basis. On the molecular level, sunscreens with a well-balanced sun protection factor/UVA-PF ratio were demonstrated to prevent UVA-induced expression of the genes associated with oxidative stress response and ECM degradation in the dermis. ${ }^{72}$ This type of protection would be particularly suitable for lightly pigmented Caucasian skin that is prone to wrinkles. Darkly pigmented and, particularly, Oriental skin could benefit from the sunscreens that filter shorter wavelength UV that affects epidermis and could exasperate the hyperpigmented lesions. Development of new personalized products that support skin barrier renewal and enhance NMF to prevent TEWS could be particularly beneficial for African skin.

Frequently, the knowledge on genetic background, gene/ environment interactions and the response to the cosmetic ingredients is not always available. One step toward more 


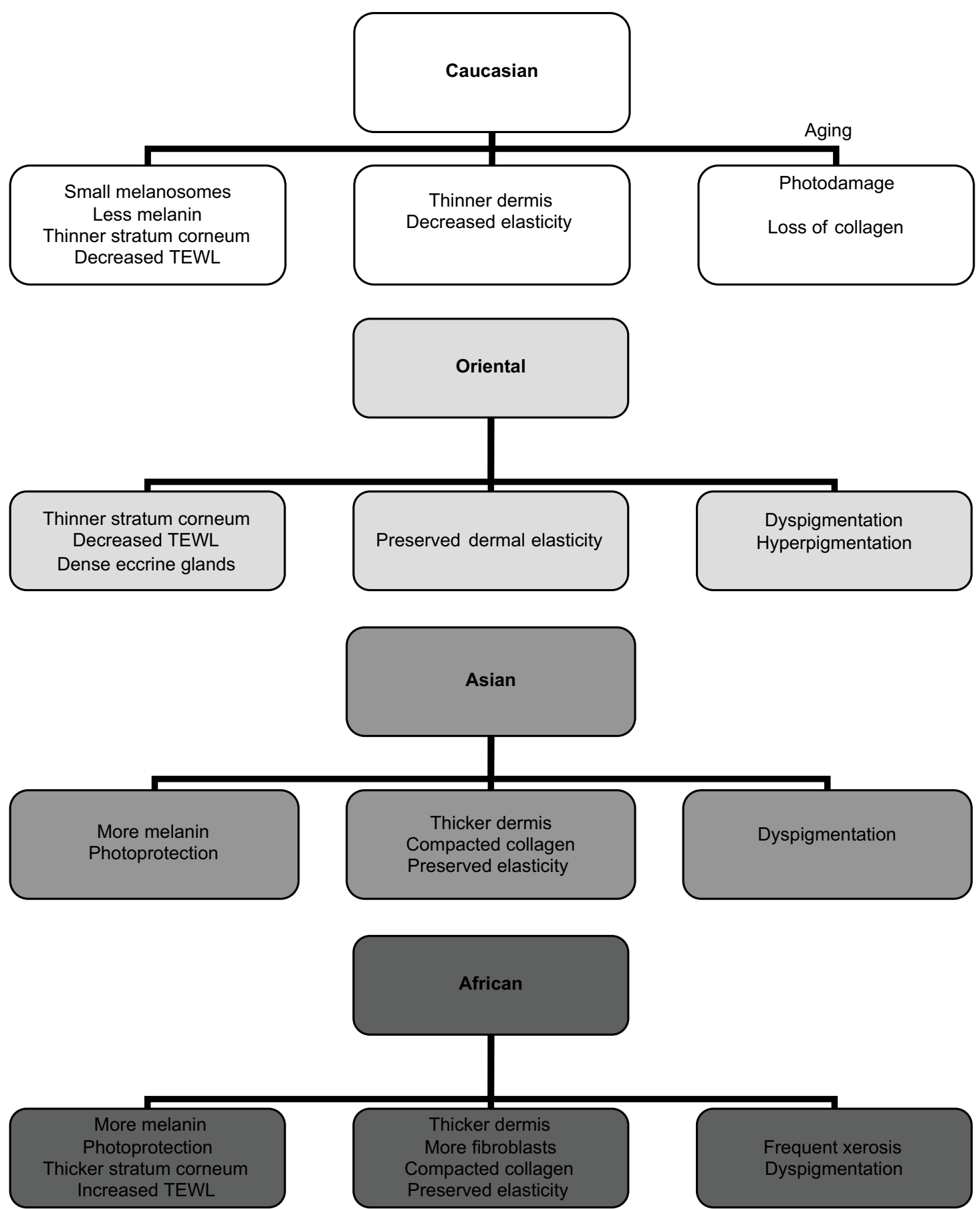

Figure I Representative differences within the epidermis and dermis among four ethnic skin types and the age-related changes typical for the traits sensitive to environmental damage.

Abbreviation: TEWL, transepidermal water loss.

complete databases would be gathering the information on the use of personal care products in the studies of consumer use practices, including the amount of the applied product and the frequency of its use. This also provides an exposure assessment of the active ingredients in such products. ${ }^{73,74}$ For instance, the awareness of the UV-induced damage is reflected by greater photoprotective measurers recorded in clinical studies among volunteers with group I/II compared to III/IV skin types ${ }^{75}$ Randomized trials also provide a useful tool to define long-term effects of the product. ${ }^{76}$

Relevant studies also describe the construction of new models of population exposure to regulated personal care products based on the recorded usage profiles. ${ }^{77,78}$ Another complementary approach to personalized information is 
through visualization techniques based on the Electronic Health Records as a summary of individual's physical health and guidance to optimal health level. Such a system has been described for several case studies and subsequently translated into a model and information visualization tools recommendations to explore multiple Electronic Health Records. ${ }^{79}$ Interestingly, one important parameter to assess the overall health status is the facial complexion of the individual. Such a factor implemented in the construction of the visualized health report might provide an alternative to the conventional, text-based clinical description as part of the personalized health information. ${ }^{80}$

\section{Conclusion}

Molecular and physiologic responses of the skin to the environmental factors that affect pigmentation, dermal elasticity and epidermal moisture are strongly dependent on the skin type. Ethnic skin phenotypes can be distinguished based on defined genotypic traits, most specifically SNP in the genes involved in biosynthesis of melanin and responsible for pigmentation. Melanin production is stimulated by UV radiation and has an important role in protecting the skin against photodamage. Skin types defined as Caucasian, Oriental, Asian and African origin demonstrate significant differences in the organization and compartmentalized sensitivity to distinct extrinsic factors. This translates further into different demands regarding preventive measures and relevant cosmetic product applications focusing on distinct aspects of skin damage and regeneration. Personalized skincare is an actively growing area with the biomedical and commercial applications that could provide new generation of skin products. Individual approach to skin, based on the recorded profiles and the in silico modeling of unique characteristics such as structural and biometric measurements, dermal/epidermal biomarkers, hormonal and stress response, could be an effective and affordable treatment of many skin conditions in the future.

\section{Disclosure}

The authors report no conflicts of interest in this work.

\section{References}

1. Flament F, Bazin R, Laquieze S, Rubert V, Simonpietri E, Piot B. Effect of the sun on visible clinical signs of aging in Caucasian skin. Clin Cosmet Investig Dermatol. 2013;6:221-232.

2. Ichihashi M, Ando H. The maximal cumulative solar UVB dose allowed to maintain healthy and young skin and prevent premature photoaging. Exp Dermatol. 2014;23 (Suppl 1):43-46.

3. D'Orazio J, Jarrett S, Amaro-Ortiz A, Scott T. UV radiation and the skin. Int J Mol Sci. 2013;14(6):12222-12248.
4. Cui R, Widlund HR, Feige E, et al. Central role of p53 in the Suntan response and pathologic hyperpigmentation. Cell. 2007;128(5):853-864.

5. Scott TL, Christian PA, Kesler MV, et al. Pigment-independent cAMPmediated epidermal thickening protects against cutaneous UV injury by keratinocyte proliferation. Exp Dermatol. 2012;21(10):771-777.

6. Widlund HR, Fisher DE. Microphthalamia-associated transcription factor: a critical regulator of pigment cell development and survival. Oncogene. 2003;22(20):3035-3041.

7. Rouzaud F, Costin GE, Yamaguchi Y, et al. Regulation of constitutive and UVR-induced skin pigmentation by melanocortin 1 receptor isoforms. FASEB J. 2006;20(11):1927-1929.

8. Fisher GJ, Wang ZQ, Datta SC, Varani J, Kang S, Voorhees JJ. Pathophysiology of premature skin aging induced by ultraviolet light. $N$ Engl J Med. 1997;337(20):1419-1428.

9. Battie C, Jitsukawa S, Bernerd F, Del Bino S, Marionnet C, Verschoore $\mathrm{M}$. New insights in photoaging, UVA induced damage and skin types. Exp Dermatol. 2014;23 (Suppl 1):7-12.

10. Fitzpatrick TB. The validity and practicality of sun-reactive skin types I through VI. Arch Dermatol. 1988;124(6):869-871.

11. Thong HY, Jee SH, Sun CC, Boissy RE. The patterns of melanosome distribution in keratinocytes of human skin as one determining factor of skin colour. Br J Dermatol. 2003;149(3):498-505.

12. Matts PJ, Dykes PJ, Marks R. The distribution of melanin in skin determined in vivo. Br J Dermatol. 2007;156(4):620-628.

13. Ito S, Wakamatsu K, Ozeki H. Chemical analysis of melanins and its application to the study of the regulation of melanogenesis. Pigment Cell Res. 2000;13 (Suppl 8):103-109.

14. Vincensi MR, d'Ischia M, Napolitano A, et al. Phaeomelanin versus eumelanin as a chemical indicator of ultraviolet sensitivity in fairskinned subjects at high risk for melanoma: a pilot study. Melanoma Res. 1998;8(1):53-58.

15. Slominski A, Tobin DJ, Shibahara S, Wortsman J. Melanin pigmentation in mammalian skin and its hormonal regulation. Physiol Rev. 2004;84(4):1155-1228.

16. Setty SR, Tenza D, Sviderskaya EV, Bennett DC, Raposo G, Marks MS. Cell-specific ATP7A transport sustains copper dependent tyrosinase activity in melanosomes. Nature. 2008;454(7208):1142-1146.

17. Chi A, Valencia JC, Hu ZZ, et al. Proteomic and bioinformatic characterization of the biogenesis and function of melanosomes. J Proteome Res. 2006;5(11):3135-3144.

18. Nordlund JJ. The melanocyte and the epidermal melanin unit: an expanded concept. Dermatol Clin. 2007;25(3):271-281.

19. Beattie PE, Dawe RS, Ferguson J, Ibbotson SH. Dose-response and time-course characteristics of UV-A1 erythema. Arch Dermatol. 2005;141(12):1549-1555.

20. Tadokoro T, Yamaguchi Y, Batzer J, et al. Mechanisms of skin tanning in different racial/ethnic groups in response to ultraviolet radiation. J Invest Dermatol. 2005;124(6):1326-1332.

21. Yamaguchi Y, Takahashi K, Zmudzka BZ, et al. Human skin responses to $\mathrm{UV}$ radiation: pigment in the upper epidermis protects against DNA damage in the lower epidermis and facilitates apoptosis. FASEB $J$. 2006;20(9):1486-1488.

22. Parra EJ. Human pigmentation variation: evolution, genetic basis, and implications for public health. Am J Phys Anthropol. 2007;(Suppl 45): 85-105.

23. Wang X, Tomso DJ, Liu X, Bell DA. Single nucleotide polymorphism in transcriptional regulatory regions and expression of environmentally responsive genes. Toxicol Appl Pharmacol. 2005;207(2 Suppl):84-90.

24. Stokowski RP, Pant PV, Dadd T, et al. A genomewide association study of skin pigmentation in a South Asian population. Am J Hum Genet. 2007;81(6):1119-1132.

25. Sulem P, Gudbjartsson DF, Stacey SN, et al. Genetic determinants of hair, eye and skin pigmentation in Europeans. Nat Genet. 2007;39(12):1443-1452.

26. Han J, Kraft P, Nan H, et al. A genome-wideassociation study identifies novel alleles associated with hair color and skin pigmentation. PLoS Genet. 2008;4(5):e1000074. 
27. Guenther CA, Tasic B, Luo L, Bedell MA, Kingsley DM. A molecular basis for classic blond hair color in Europeans. Nat Genet. 2014;46(7):748-752.

28. Praetorius C, Grill C, Stacey SN, et al. A polymorphism in IRF4 affects human pigmentation through a tyrosinase-dependent MITF/TFAP2A pathway. Cell. 2013;155(5):1022-1033.

29. Visser M, Palstra RJ, Kayser M. Human skin color is influenced by an intergenic DNA polymorphism regulating transcription of the nearby BNC2 pigmentation gene. Hum Mol Genet. 2014;23(21):5750-5762.

30. Visser M, Palstra RJ, Kayser M. Allele-specific transcriptional regulation of IRF4 in melanocytes is mediated by chromatin looping of the intronic rs 12203592 enhancer to the IRF4 promoter. Hum Mol Genet. 2015;24(9):2649-2661.

31. Sturm RA. Molecular genetics of human pigmentation diversity. Hum Mol Genet. 2009;18(R1):R9-R17.

32. Sturm RA, Duffy DL. Human pigmentation genes under environmental selection. Genome Biol. 2012;13(9):248.

33. Alaluf $\mathrm{S}$, Heath A, Carter N, et al. Variation in melanin content and composition in type V and VI photoexposed and photoprotected human skin: the dominant role of DHI. Pigment Cell Res. 2001;14(5):337-347.

34. Vashi NA, de Castro Maymone MB, Kundu RV. Aging diferences in Ethnic skin. J Clin Aesthet Dermatol. 2016;9(1):31-38.

35. Brenner M, Hearing VJ. The protective role of melanin against UV damage in human skin. Photochem Photobiol. 2008;84(3):539-549.

36. Berardesca E, de Rigal J, Leveque JL, Maibach HI. In vivo biophysical characterization of skin physiological differences in races. Dermatologica. 1991;182(2):89-93.

37. Sugino K, Imokawa G, Maibach H. Ethnic differences in stratum corneum lipid in relation to stratum corneum function. J Invest Dermatol. 1993;100(1):594.

38. Brissett AE, Naylor MC. The aging African-American face. Facial Plast Surg. 2010;26(2):154-163.

39. Elias PM, Menon G, Wetzel BK, Williams JJ. Evidence that stress to the epidermal barrier influenced the development of pigmentation in humans. Pigment Cell Melanoma Res. 2009;22(4):420-434.

40. Gunathilake R, Schurer NY, Shoo BA, et al. pH-regulated mechanisms account for pigment-type differences in epidermal barrier function. J Invest Dermatol. 2009;129(7):1719-1729.

41. Montagna W, Prota G, Kenney J. The structure of black skin. In: Montagna W, Prota G, Kenney J, editors. Black Skin Structure and Function. Gulf Professional Publishing Oxford, United Kingdom; 1993.

42. Montagna W, Carlisle K. The architecture of black and white facial skin. J Am Acad Dermatol. 1991;24(6 Pt 1):929-937.

43. Rawlings AV. Ethnic skin types: are there differences in skin structure and function? Int J Cosmet Sci. 2006;28(2):79-93.

44. Lober CW, Fenske NA. Photoaging and the skin: differentiation and clinical response. Geriatrics. 1990;45(4):36-40.

45. Galzote C, Estanislao R, Suero MO, et al. Characterization of facial skin of various Asian populations through visual and noninvasive instrumental evaluations: influence of age and skincare habits. Skin Res Technol. 2013;19(4):454-465.

46. de Rigal J, Des Mazis I, Diridollou S, et al. The effect of age on skin color and color heterogeneity in four ethnic groups. Skin Res Technol. 2010;16(2):168-178

47. Goh SH. The treatment of visible signs of senescence: the Asian experience. Br J Dermatol. 1990;122 (Suppl 35):105-109.

48. Vierkötter A, Krämer U, Sugiri D, et al. Development of lentigines in German and Japanese women correlates with variants in the SLC45A2 gene. J Invest Dermatol. 2012;132(3 Pt 1):733-736.

49. Nouveau-Richard S, Yang Z, Mac-Mary S, et al. Skin aging: a comparison between Chinese and European populations. A pilot study. J Dermatol Sci. 2005;40(3):187-193.

50. Morizot F, Guehenneux S, Dheurle S, et al. Do features of aging differ between Asian and Caucasian women. $J$ Invest Dermatol. 2004;123:A67.
51. Perner D, Vierkötter A, Sugiri D, et al. Association between sunexposure, smoking behaviour and plasma antioxidant levels with the different manifestation of skin ageing signs between Japanese and German women-a pilot study. J Dermatol Sci. 2011;62(2):138-140.

52. Wesley NO, Maibach HI. Racial (ethnic) differences in skin properties: the objective data. Am J Clin Dermatol. 2003;4(12):843-860.

53. Diridollou S, de Rigal J, Querleux B, Leroy F, Holloway Barbosa V. Comparative study of the hydration of thestratum corneum between four ethnic groups: influence of age. Int J Dermatol. 2007;46 (Suppl 1): $11-14$.

54. Chu M, Kollias N. Documentation of normal stratum corneum scaling in an average population: features of differences among age, ethnicity and body site. Br J Dermatol. 2011;164(3):497-507.

55. Lodén M. Role of topical emollients and moisturizers in the treatment of dry skin barrier disorders. Am J Clin Dermatol. 2003;4(11):771-788.

56. Nolan K, Marmur E. Moisturizers: reality and the skin benefits. Dermatol Ther. 2012;25(3):229-233.

57. Draelos ZD. New treatments for restoring impaired epidermal barrier permeability: skin barrier repair creams. Clin Dermatol. 2012;30(3):345-348.

58. McGrath JA, Robinson MK, Binder RL. Skin differences based on age and chronicity of ultraviolet exposure: results from a gene expression profiling study. Br J Dermatol. 2012;166 (Suppl 2):9-15.

59. Kim JM, Jung YS, Sungur EA, Han KH, Park C, Sohn I. A copula method for modeling directional dependence of genes. BMC Bioinformatics. 2008;9:225.

60. ElBakry O, Ahmad MO, Swamy MN. Inference of gene regulatory networks with variable time delay from time-series microarray data. IEEE/ACM Trans Comput Biol Bioinform. 2013;10(3):671-687.

61. Benech PD, Patatian A. From experimental design to functional gene networks: DNA microarray contribution to skin ageing research. Int J Cosmet Sci. 2014;36(6):516-526.

62. Schweitzer J, Maibach H. Pharmacogenomics in dermatology: taking patient treatment to the next level. J Dermatolog Treat. 2015;26(1):94-96.

63. Shoaib M, Rameez MA, Hussain SA, Madadin M, Menezes RG. Personalized medicine in a new genomic Era: ethical and legal aspects. Sci Eng Ethics. 2017;23(4):1207-1212.

64. Has C, Sitaru C. Molecular dermatology comes of age. Methods Mol Biol. 2013;961:1-16.

65. Berardesca E, Maibach H. Racial differences in skin pathophysiology. J Am Acad Dermatol. 1996;34(4):667-672.

66. Roh M, Han M, Kim D, Chung K. Sebum output as a factor contributing to the size of facial pores. Br J Dermatol. 2006;155(5):890-894.

67. Sugiyama-Nakagiri Y, Sugata K, Hachiya A, Osanai O, Ohuchi A, Kitahara T. Ethnic differences in the structural properties of facial skin. J Dermatol Sci. 2009;53(2):135-139.

68. Ma Q, Lu AY. Pharmacogenetics, pharmacogenomics, and individualized medicine. Pharmacol Rev. 2011;63(2):437-459.

69. Krutmann J, Bouloc A, Sore G, Bernard BA, Passeron T. The skin aging exposome. J Dermatol Sci. 2017;85(3):152-161

70. Witorsch RJ, Thomas JA. Personal care products and endocrine disruption: a critical review of the literature. Crit Rev Toxicol. 2010;40 (Suppl 3):1-30.

71. Kim SM, Oh BH, Lee YW, Choe YB, Ahn KJ. The relation between the amount of sunscreen applied and the sun protection factor in Asian skin. J Am Acad Dermatol. 2010;62(2):218-222.

72. Seité S, Reinhold K, Jaenicke T, Brenden H, Krutmann J, Grether-Beck S. Broad-spectrum moisturizer effectively prevents molecular reactions to UVA radiation. Cutis. 2012;90(6):321-326.

73. Loretz LJ, Api AM, Barraj LM, et al. Exposure data for cosmetic products: lipstick, body lotion, and face cream. Food Chem Toxicol. 2005;43(2):279-291.

74. Biesterbos JW, Dudzina T, Delmaar CJ, et al. Usage patterns of personal care products: important factors for exposure assessment. Food Chem Toxicol. 2013;55:8-17. 
75. Gould M, Farrar MD, Kift R, et al. Sunlight exposure and photoprotection behaviour of white Caucasian adolescents in the UK. J Eur Acad Dermatol Venereol. 2015;29(4):732-737.

76. Hughes MC, Williams GM, Baker P, Green AC. Sunscreen and prevention of skin aging: a randomized trial. Ann Intern Med. 2013;158(11):781-790.

77. McNamara C, Rohan D, Golden D, et al. Probabilistic modelling of European consumer exposure to cosmetic products. Food Chem Toxicol. 2007;45(11):2086-2096.

78. Nohynek GJ, Antignac E, Re T, Toutain H. Safety assessment of personal care products/cosmetics and their ingredients. Toxicol Appl Pharmacol. 2010;243(2):239-259.

79. Wang TD, Wongsuphasawat K, Plaisant C, Shneiderman B. Extracting insights from electronic health records: case studies, a visual analytics process model, and design recommendations. J Med Syst. 2011;35(5):1135-1152.

80. Hsiao JH, Chang H. Visualizing health: a novel visualization method for personalized health summarization and guidance. Stud Health Technol Inform. 2013;192:1005.

81. Liu F, Visser M, Duffy DL, et al. Genetics of skin color variation in Europeans: genome-wide association studies with functional followup. Hum Genet. 2015;134(8):823-835.

82. Kanetsky PA, Swoyer J, Panossian S, Holmes R, Guerry D, Rebbeck TR. A polymorphism in the agouti signaling protein gene is associated with human pigmentation. Am J Hum Genet. 2002;70(3):770-775.

83. Sulem P, Gudbjartsson DF, Stacey SN, et al. Two newly identified genetic determinants of pigmentation in Europeans. Nat Genet. 2008;40(7):835-837.

84. Jacobs LC, Wollstein A, Lao O, et al. Comprehensive candidate gene study highlights UGT1A and BNC2 as new genes determining continuous skin color variation in Europeans. Hum Genet. 2012;132(2):147-158.

85. Lao O, de Gruijter JM, van Duijn K, Navarro A, Kayser M. Signatures of positive selection in genes associated with human skin pigmentation as revealed from analyses of single nucleotide polymorphisms. Ann Hum Genet. 2007;71(Pt 3):354-369.

86. Alonso S, Izagirre N, Smith-Zubiaga I, et al. Complex signatures of selection for the melanogenic loci TYR, TYRP1 and DCT in humans. BMC Evol Biol. 2008;8:74.

87. Ji H, Sharpless NE, Wong KK. EGFR targeted therapy: view from biological standpoint. Cell Cycle. 2006;5(18):2072-2076.

88. Saternus R, Pilz S, Gräber S, et al. A closer look at evolution: variants (SNPs) of genes involved in skin pigmentation, including EXOC2, TYR, TYRP1, and DCT, are associated with 25(OH)D serum concentration. Endocrinology. 2015;156(1):39-47.
89. Nan H, Kraft P, Qureshi AA, et al. Genome-wide association study of tanning phenotype in a population of European ancestry. $J$ Invest Dermatol. 2009;129(9):2250-2257.

90. Picardo M, Cardinali G. The genetic determination of skin pigmentation: KITLG and the KITLG/c-Kit pathway as key players in the onset of human familial pigmentary diseases. J Invest Dermatol. 2011;131(6):1182-1185.

91. Suzuki I, Cone RD, Im S, Nordlund J, Abdel-Malek ZA. Binding of melanotropic hormones to the melanocortin receptor MC1R on human melanocytes stimulates proliferation and melanogenesis. Endocrinology. 1996;137(5):1627-1633.

92. Kadekaro AL, Kanto H, Kavanagh R, Abdel-Malek Z. Significance of the melanocortin 1 receptor in regulating human melanocyte pigmentation, proliferation and survival. Ann N Y Acad Sci. 2003;994 359-365.

93. Beaumont KA, Liu YY, Sturm RA. The melanocortin-1 receptor gene polymorphism and association with human skin cancer. Prog Mol Biol Trans Sci. 2009;88:85-153.

94. Savage SA, Gerstenblith MR, Goldstein AM, et al. Nucleotide diversity and population differentiation of the melanocortin 1 receptor gene, MC1R. BMC Genet. 2008;9:31.

95. Nakayama K, Soemantri A, Jin F, et al. Identification of novel functional variants of the melanocortin 1 receptor gene originated from Asians. Hum Genet. 2006;119(3):322-330.

96. Yuasa I, Umetsu K, Harihara S, et al. OCA2 481Thr, a hypofunctional allele in pigmentation, is characteristic of northeastern Asian populations. J Hum Genet. 2007;52(8):690-693.

97. Donnelly MP, Paschou P, Grigorenko E, et al. A global view of the OCA2-HERC2 region and pigmentation. Hum Genet. 2012;131(5): 683-696.

98. Edwards M, Bigham A, Tan J, et al. Association of the OCA2 polymorphism His615Arg with melanin content in east Asian populations: further evidence of convergent evolution of skin pigmentation. PLoS Genet. 2010;6(3):e1000867.

99. Basu Mallick C, Iliescu FM, Mols M, et al. The light skin allele of SLC24A5 in South Asians and Europeans shares identity by descent. PLoS Genet. 2013;9(11):e1003912

100. Alaluf S, Barrett K, Blount M, Carter N. Ethnic variation in tyrosinase and TYRP1 expression in photoexposed and photoprotected human skin. Pigment Cell Res. 2003;16(1):35-42.

101. Rooryck C, Morice F, Didier L, Taieb A, Arveiler B. Genetic basis of oculocutaneous albinism. Expert Rev Dermatol. 2009;4: $611-622$.
Clinical, Cosmetic and Investigational Dermatology

\section{Publish your work in this journal}

Clinical, Cosmetic and Investigational Dermatology is an international, peer-reviewed, open access, online journal that focuses on the latest clinical and experimental research in all aspects of skin disease and cosmetic interventions. This journal is included on PubMed. The manuscript management system is completely online
Dovepress

and includes a very quick and fair peer-review system, which is all easy to use. Visit http://www.dovepress.com/testimonials.php to read real quotes from published authors 